\title{
Urgent care center wait times increase for COVID-19 results in August 2020, with rapid testing availability limited
}

\author{
Laurie C Yousman ${ }^{1 \dagger}$, Akshay Khunte ${ }^{1 \dagger}$, Walter Hsiang ${ }^{1}$, Siddharth Jain ${ }^{1}$, Howard Forman ${ }^{2}$ and Daniel Wiznia ${ }^{3^{*}}$
}

\begin{abstract}
Background: In a response to the pandemic, urgent care centers (UCCS) have gained a critical role as a common location for COVID-19 testing. We sought to characterize the changes in testing accessibility at UCCs between March and August 2020 on the basis of testing availability (including rapid antigen testing), wait time for test results, cost of visits, and cost of tests.
\end{abstract}

Methods: Data were collected using a secret shopper methodology. Researchers contacted 250 UCCs in 10 states. Investigators used a standardized script to survey centers on their COVID-19 testing availability and policies. UCCs were initially contacted in March and re-called in August. T-tests and chi-square tests were conducted to identify differences between March and August data and differences by center classification.

Results: Our results indicate that both polymerase chain reaction (PCR) tests to detect COVID-19 genetic material and rapid antigen COVID-19 tests have increased in availability. However, wait times for PCR test results have significantly increased to an average of 5.79 days. Additionally, a high proportion of UCCs continue to charge for tests and visits and no significant decrease was found in the proportion of UCCs that charge for COVID-19 testing from March to August. Further, no state reported a majority of UCCs with rapid testing available, indicating an overall lack of rapid testing.

Conclusions: From March to August, COVID-19 testing availability gradually improved. However, many barriers lie in access to COVID-19 testing, including testing costs, visit costs, and overall lack of availability of rapid testing in the majority of UCCs. Despite the passage of the CARES Act, these results suggest that there is room for additional policy to improve accessibility to testing, specifically rapid testing.

Keywords: COVID-19, COVID-19 testing, Urgent care center, Access to care

\section{Introduction}

With the onset of the COVID-19 pandemic, urgent care centers (UCCs) have become a common access point for testing, $[1,2]$ and over the last few months the availability and cost of COVID-19 testing at UCCs have

\footnotetext{
* Correspondence: daniel.wiznia@yale.edu

Laurie C Yousman and Akshay Khunte are co-first authors.

${ }^{+}$Laurie C Yousman and Akshay Khunte contributed equally to this work.

${ }^{3}$ Yale University School of Medicine, Department of Orthopaedics and Rehabilitation, 800 Howard Avenue, New Haven, Connecticut 06520, USA Full list of author information is available at the end of the article
}

evolved.[3, 4] In particular, the Coronavirus Aid, Relief, and Economic Security (CARES) Act was passed in March 2020 with the goal of expanding access to testing by providing coverage of COVID-19 testing for all patients, regardless of insurance status.

Existing literature has explored many aspects of the COVID-19 testing landscape, including addressing rapidly increasing demand for tests, lack of testing resources, supply chain barriers, and long turnaround times.[5, 6] Several different locations for COVID-

C C The Author(s). 2021 Open Access This article is licensed under a Creative Commons Attribution 4.0 International License, which permits use, sharing, adaptation, distribution and reproduction in any medium or format, as long as you give appropriate credit to the original author(s) and the source, provide a link to the Creative Commons licence, and indicate if changes were made. The images or other third party material in this article are included in the article's Creative Commons licence, unless indicated otherwise in a credit line to the material. If material is not included in the article's Creative Commons licence and your intended use is not permitted by statutory regulation or exceeds the permitted use, you will need to obtain permission directly from the copyright holder. To view a copy of this licence, visit http://creativecommons.org/licenses/by/4.0/ The Creative Commons Public Domain Dedication waiver (http://creativecommons.org/publicdomain/zero/1.0/) applies to the data made available in this article, unless otherwise stated in a credit line to the data. 
19testing have also been highlighted by the existing literature, including physician offices, in-patient hospital settings, emergency rooms, community health centers, walk-in retail clinics, and urgent care centers.[7] Additionally, the cost of COVID-19 testing has been reported for top US hospitals, and has further been broken down into average cost by different testing providers. $[7,8]$.

While existing research delves into the barriers that impact lack of accessibility to COVID-19 testing,[9] there are many gaps in the literature, including studies with a direct focus on UCCs. To our knowledge, no such study has examined COVID-19 testing at urgent care centers and specifically compared availability of testing during time periods before and after the passage of the CARES Act. Additionally, while some literature points out the extra barriers that uninsured patients may face when seeking testing and care for COVID-19,[10, 11] there is a lack of existing literature specifically focused characterizing the multiple cost barriers to testing for uninsured patients in light of the evolving costs of COVID-19 testing. We examined how availability of testing, wait times for test results, and cost of testing have changed at UCCs from March 2020 to August 2020 in the United States.

\section{Methods}

This study received IRB exemption from the Yale School of Medicine. We utilized a secret shopper methodology outlined in previous studies.[12-14] UCCs were defined as walk-in clinics separate from hospital-affiliated or freestanding emergency departments. Due to many states exhibiting extremely caseloads,[15] researchers focused on states considered COVID-19 hotspots. 25 UCCs were randomly selected from each of the 10 states with the highest COVID-19 caseloads in March 2020[16] using the Solv Health Urgent Care Directory, [17] containing approximately 11,000 UCCs across the United States. In each individual state, every UCC in the directory was assigned a numeric value and a random number generator was used to select 25 UCCs from each state.

Investigators called UCCs posing as uninsured patients seeking COVID-19 testing. A standardized script was used to inquire about availability of testing, estimated test result wait time, and whether testing and UCC visits were free for uninsured patients. Rapid testing was defined as $\mathrm{a}<2 \mathrm{~h}$ wait time. As the rapid antigen test is often conducted in conjunction with the PCR test and is less reliable than the PCR test,[18] it was measured as a separate variable and not included in the August calculation of estimated wait time. The same 250 UCCs were contacted initially in March 2020 and called again in August 2020.
Each UCC was classified into one of four center types: (1) Non-affiliated, defined as a stand-alone or chain of UCCs with no affiliation to a private practice or hospital network, (2) Extension of Private Practice, defined as a UCC that is operated by and connected to a private practice, (3) Extension of Hospital/Health Network, defined as a UCC associated with a non-academic hospital or health network, or (4) Academic, defined as a UCC associated with a teaching hospital. The primary outcome variable was the availability of COVID-19 testing at centers in March and August. Additionally, data were collected on center requirements for testing, center policy on the cost of testing before and after the passage of the CARES Act, and expected wait time for test results.

Statistical analysis was performed using JMP Pro Version 15. Comparisons between March and August calls and comparisons between testing availability by center type were conducted using 2 sample t-tests and chisquare tests to generate differences and odds ratios $(\mathrm{OR})$, respectively. For odds ratios, the non-exposure group was considered March while the exposed group was considered to be August. The outcomes were each of the first four variables listed in Table 1. P-values lower than 0.05 were considered statistically significant, therefore, $95 \%$ confidence intervals $(\mathrm{CI})$ were used.

\section{Results}

Table 1 lists changes in testing accessibility from March to August. There was a significant increase in availability of general PCR testing (OR 4.43, $95 \%$ CI 1.99-9.84, pvalue $=0.0001)$. Rapid testing was unavailable in March. In August, some rapid testing was available $(8.40 \%$ ( $n=$ $21)$ ). There was no significant change in the proportion of UCCs charging for testing (OR 0.78, $95 \%$ CI 0.32, $1.92, p$-value $=0.5874)$. There was a decrease in the proportion charging for visits (OR $0.16,95 \%$ CI $0.05,0.53$, $p$-value $=0.0008$ ). The proportions of centers charging for both visits and tests remained high in August. Wait times for non-rapid test results significantly increased from March to August (0.92 days, $95 \%$ CI 0.17-1.67, pvalue $=0.0169)$ to an average of 5.79 days.

Table 2 lists changes in testing accessibility from March to August for each individual state surveyed. State level results reveal that testing availability significantly increased in all 10 states. There was an extremely low prevalence of rapid testing available, with no state indicating a majority of centers offering rapid testing and four out of ten states having no centers that offered rapid testing. Wait times for PCR test results did not decrease significantly in any individual state, and increased significantly in Florida.

Table 3 displays differences in PCR testing availability by center classification. In a comparison between all four center types, there was a significant difference. Non- 
Table 1 Variables Characterizing Accessibility of COVID-19 Testing at UCCS

\begin{tabular}{|c|c|c|c|}
\hline & $\begin{array}{l}\text { Proportion } \\
\% \text { (n) }\end{array}$ & Univariate odds ratio $(95 \% \mathrm{Cl})$ & $P$ value \\
\hline \multicolumn{4}{|l|}{ Testing Available } \\
\hline March $(n=250)$ & $24.00 \%(60)$ & Ref & \\
\hline August $(n=250)$ & $66.00 \%(165)$ & $4.43(1.99,9.84)$ & 0.0001 \\
\hline \multicolumn{4}{|c|}{ If Testing Available, Only Testing Symptomatic Patients } \\
\hline March $(n=60)$ & $98.33 \%(59)$ & Ref & \\
\hline August $(n=163)$ & $22.70 \%(37)$ & $0.0050(0.0007,0.0372)$ & $<0.0001$ \\
\hline \multicolumn{4}{|c|}{ If Testing Available, Charge for Test } \\
\hline March $(n=53)$ & $86.79 \%(46)$ & Ref & \\
\hline August $(n=153)$ & $83.66 \%(128)$ & $0.78(0.32,1.92)$ & 0.5874 \\
\hline \multicolumn{4}{|c|}{ If Testing Available, Charge for Visit } \\
\hline March $(n=59)$ & $94.92 \%(56)$ & Ref & 0.0008 \\
\hline \multirow[t]{2}{*}{ August $(n=157)$} & $74.52 \%(117)$ & $0.16(0.05,0.53)$ & \\
\hline & Mean (days) & Difference $(95 \% \mathrm{Cl})$ & Pvalue \\
\hline \multicolumn{4}{|c|}{ If Testing Available, Result Wait Time } \\
\hline March $(n=52)$ & 4.87 & Ref & 0.0169 \\
\hline August $(n=136)$ & 5.79 & $+0.92(0.17,1.67)$ & \\
\hline
\end{tabular}

Comparisons between March and August data were conducted. There were 10 states originally contacted in March and re-called in August.

affiliated UCCs demonstrated the highest rates of PCR testing availability, while extension of private practice UCCs demonstrated the lowest.

\section{Discussion}

While accessibility of COVID-19 testing at UCCs has slowly improved since March, over a third of UCCs still do not offer testing. Additionally, there is still a severe lack of rapid testing, with only $8.40 \%$ of centers able to provide rapid testing in August. Additionally, wait times for test results have significantly increased between
March and August, indicating an insufficiency in the capacity to process tests in the United States.

The CARES Act was intended to increase accessibility of COVID-19 testing,[19] however, our findings indicate that the CARES Act has not decreased the cost of COVID-19 testing for uninsured patients at UCCs. The large majority of UCCs continue to charge for both testing and visits, contradictory to the aims of the CARES Act, and this may discourage patients from pursuing testing. In particular, this continued charge for COVID19 testing may disproportionately affect uninsured and underinsured individuals.

Table 2 State-Level UCC COVID-19 Testing Availability and Wait Times

\begin{tabular}{|c|c|c|c|c|c|c|c|}
\hline \multirow[b]{2}{*}{ State $(n=25)$} & \multicolumn{3}{|c|}{ Testing Available } & \multirow[t]{2}{*}{ Rapid Testing Available (August) } & \multicolumn{3}{|c|}{ Mean Wait Time (days) } \\
\hline & March & August & $P$-Value & & March & August & $P$-Value \\
\hline California & $4 \%(1)$ & $28 \%(7)$ & 0.0206 & $0 \%(0)$ & N/A & 6.81 & - \\
\hline Colorado & $8 \%(2)$ & $48 \%(12)$ & 0.0016 & $4 \%(1)$ & 4.50 & 5.00 & 0.6158 \\
\hline Florida & $32 \%(8)$ & $64 \%(16)$ & 0.0235 & $8 \%(2)$ & 4.00 & 7.12 & 0.0304 \\
\hline Georgia & $8 \%(2)$ & $68 \%(17)$ & $<0.0001$ & $16 \%(4)$ & 5.00 & 5.29 & 0.5762 \\
\hline Illinois & $24 \%(6)$ & $72 \%(18)$ & 0.0007 & $16 \%(4)$ & 4.92 & 4.33 & 0.1873 \\
\hline Louisiana & $16 \%(4)$ & $76 \%(19)$ & $<0.0001$ & $28 \%(7)$ & 5.75 & 4.32 & 0.1263 \\
\hline Massachusetts & $40 \%(10)$ & $92 \%(23)$ & $<0.0001$ & $12 \%(3)$ & 5.80 & 6.20 & 0.8790 \\
\hline New Jersey & $32 \%(8)$ & $60 \%(15)$ & 0.0470 & $0 \%(0)$ & 5.19 & 7.53 & 0.1448 \\
\hline New York & $40 \%(10)$ & $76 \%$ (19) & 0.0099 & $0 \%(0)$ & 4.80 & 6.24 & 0.4738 \\
\hline Washington & $36 \%(9)$ & $76 \%(19)$ & 0.0044 & $0 \%(0)$ & 3.79 & 4.75 & 0.3669 \\
\hline
\end{tabular}


Table 3 Testing Availability by Center Classification

Proportion of Centers Offering Testing $\quad$ Odds Ratio $(95 \% \mathrm{Cl})$
$\%(\mathrm{n})$

PCR Testing Availability

0.0077

\begin{tabular}{llll}
\hline Non-affiliated $(n=143)$ & $70.63 \%(101)$ & Ref & \\
Extension of Private Practice $(n=38)$ & $42.11 \%(16)$ & $3.31(1.58,6.91)$ & 0.0015 \\
Extension of Hospital/Health Network $(n=59)$ & $71.19 \%(42)$ & $0.973(0.50,1.90)$ & 0.9369 \\
Academic Hospital $(n=10)$ & $60.00 \%(6)$ & $1.60(0.43,5.97)$ & 0.4819 \\
\hline
\end{tabular}

Individual urgent care centers were classified into one of four categorizations. Chi-square analysis was only performed on availability of PCR testing and not rapid testing due to low prevalence of rapid testing in each center type

The prevalence of uninsured individuals and those who cannot afford testing may be compounded by the weakened economy, hampered by the pandemic. In 2019, $9.2 \%$ of people were uninsured, and $55.4 \%$ of people had employer-provided health coverage.[20] As record numbers of Americans lose their jobs,[21] the already significant proportion of the population that is uninsured or in poverty will continue to climb, exacerbating cost barriers to COVID-19 testing. Uninsured status has already been proven to be a health risk for a multitude of healthcare disparities,[22] and it seems likely that this issue will be compounded on several fronts by the COVID-19 pandemic and continued cost barriers to testing.

Limitations include our focus on UCCs in specific states, which may not fully represent testing capabilities across the entire United States. Additionally, not all states have gone through waves of the pandemic concurrently, so the March versus August comparison may compare testing accessibility with varying levels of regional demand.

In conclusion, as greater than five-day old test results have limited clinical utility, future research should examine policy and legislation that can advances the deployment of rapid testing.

\section{Abbreviations}

UCC: Urgent care center

\section{Acknowledgements}

Not applicable.

\section{Authors' contributions}

LY, AK, and SJ collected surveys collecting data on the availability of COVID19 testing at UCCS. LY and AK conducted data analysis on the generated dataset and generated tables 1-3. WH, HF, and DW were responsible for study design and oversaw data collection. LY wrote the main manuscript text and DW provided revisions. All authors read and approved the final manuscript.

\section{Funding}

The authors declare that no funding was received for this research.

\section{Availability of data and materials}

The datasets used and/or analyzed during the current study are available from the corresponding author on reasonable request.

\section{Declarations}

Ethics approval and consent to participate

This study received an exemption waiver from the Yale IRB. Informed consent was not obtained for this study because we did not research direct behavior of the individuals called, we simply assessed the clinic's policies, as approved of by the Yale IRB. It would be impractical to obtain a subject's authorization for this process as knowledge of the survey may bias the results, as some clinics may be more likely to accept a patient's insurance or change a patient's referral status or change a patient's appointment wait time if they know they are being surveyed. The secret shopper survey was conducted in concordance with the follow guidelines: Clinic information was obtained from search engines and urgent care center databases. Each office was contacted over the phone two times, once in March and again in August. A standardized script was be used to inquire about clinic policies surrounding Covid-19 testing. No identifying data were collected about the individual who answered the phone, only demographic information about the clinic itself. All research was performed in accordance with the Declaration of Helsinki.

\section{Consent for publication}

Not applicable

\section{Competing interests}

The authors declare that they have no competing interests.

\section{Author details}

${ }^{1}$ Yale University School of Medicine, New Haven, USA. ${ }^{2}$ Yale University School of Medicine, Department of Radiology, New Haven, USA. ${ }^{3}$ Yale University School of Medicine, Department of Orthopaedics and Rehabilitation, 800 Howard Avenue, New Haven, Connecticut 06520, USA.

Received: 7 January 2021 Accepted: 26 March 2021

Published online: 08 April 2021

\section{References}

1. Ratwani RM, Brennan D, Sheahan W, et al. A descriptive analysis of an ondemand telehealth approach for remote COVID-19 patient screening. J Telemed Telecare. Published online July 23, 2020:1357633 × 2094333. doi: https://doi.org/10.1177/1357633X20943339

2. Zwald ML, Lin W, Sondermeyer Cooksey GL, et al. Rapid Sentinel Surveillance for COVID-19 - Santa Clara County, California, March 2020. MMWR Morb Mortal Wkly Rep. 2020;69(14):419-421. doi:https://doi.org/10.1 5585/mmwr.mm6914e3

3. Ward S, Lindsley A, Courter J, Assa'ad A. Clinical testing for COVID-19. J Allergy Clin Immunol. 2020;146(1):23-34. doi:https://doi.org/10.1016/j.jaci.202 0.05 .012

4. Cheng MP, Papenburg J, Desjardins M, et al. Diagnostic Testing for Severe Acute Respiratory Syndrome-Related Coronavirus 2: A Narrative Review. Ann Intern Med. 2020;172(11):726-734. doi:https://doi.org/10.7326/M20-1301

5. Ravi N, Cortade DL, Ng E, Wang SX. Diagnostics for SARS-CoV-2 detection: A comprehensive review of the FDA-EUA COVID-19 testing landscape. Biosens Bioelectron. 2020;165:112454. doi:https://doi.org/10.1016/j.bios.2020.112454

6. Esbin MN, Whitney ON, Chong S, Maurer A, Darzacq X, Tjian R. Overcoming the bottleneck to widespread testing: a rapid review of nucleic acid testing approaches for COVID-19 detection. RNA. 2020;26(7):771-783. doi:https://doi. org/10.1261/rna.076232.120 
7. Meiselbach MK, Bai G, Anderson GF. Charges of COVID-19 Diagnostic Testing and Antibody Testing Across Facility Types and States. J Gen Intern Med. Published online September 15, 2020. doi:https://doi.org/10.1007/s11 606-020-06198-y

8. Xiao R, Rathi VK. Price Transparency for COVID-19 Testing Among Top US Hospitals. J Gen Intern Med. Published online September 18, 2020. doi: https://doi.org/10.1007/s11606-020-06197-z

9. Souch JM, Cossman JS. A Commentary on Rural-Urban Disparities in COVID19 Testing Rates per 100,000 and Risk Factors. J Rural Health. Published online June 2020. doi:https://doi.org/10.1111/jrh.12450

10. Jiang DH, McCoy RG. Planning for the Post-COVID Syndrome: How Payers Can Mitigate Long-Term Complications of the Pandemic. J Gen Intern Med. Published online July 22, 2020. doi:https://doi.org/10.1007/s11606-02006042-3

11. Gaffney A, Himmelstein DU, Woolhandler S. COVID-19 and US Health Financing: Perils and Possibilities. Int J Health Serv. 2020;50(4):396-407. doi: https://doi.org/10.1177/0020731420931431

12. Hsiang WR, Wiznia D, Yousman L, et al. Urgent Care Centers Delay Emergent Surgical Care Based on Patient Insurance Status in The United States. Ann Surg. 2020;272(4):548-553. doi:https://doi.org/10.1097/SLA. 0000000000004373

13. Wiznia DH, Schneble CA, O'Connor MI, Ibrahim SA. Musculoskeletal Urgent Care Centers in Connecticut Restrict Patients with Medicaid Insurance Based on Policy and Location. Clin Orthop. 2020;478(7):1443-1449. doi:https://doi. org/10.1097/CORR.0000000000000957

14. Hsiang W, McGeoch C, Lee S, et al. The effect of insurance type on access to inguinal hernia repair under the Affordable Care Act. Surgery. 2018;164(2): 201-205. doi:https://doi.org/10.1016/j.surg.2018.03.013

15. COVID-19 United States Cases by County. Johns Hopkins Coronavirus Resource Center. Accessed February 18, 2021. https://coronavirus.jhu.edu/ us-map

16. Hsiang W, Forman $\mathrm{H}$, Jain S, et al. COVID-19 testing capabilities at urgent care centers in states with greatest disease burden. F1000Research. 2020;9: 328. doi:https://doi.org/10.12688/f1000research.23203.1

17. Solv Health. Urgent Care Locations Near Me. Solv Health. https://www. solvhealth.com/urgent-care

18. Tan AS, Nerurkar SN, Tan WCC, Goh D, Lai CPT, Poh Sheng Yeong J. The Virological, Immunological, and Imaging Approaches for COVID-19 Diagnosis and Research. SLAS Technol TransI Life Sci Innov. Published online August 18, 2020:247263032095024. doi:https://doi.org/10.1177/247263032 0950248

19. McConnell M. CARES Act.; 2020. https://www.congress.gov/bill/116thcongress/senate-bill/3548/text?q=product+actualizaci\%C3 \%B3n

20. Keisler-Starkey K, Bunch LN. Health Insurance Coverage in the United States: 2019. U.S. Census Bureau; 2020. https://www.census.gov/content/dam/ Census/library/publications/2020/demo/p60-271.pdf

21. Cho SJ, Winters JV. The Distributional Impacts of Early Employment Losses from COVID-19. SSRN Electron J. Published online 2020. doi:https://doi.org/1 $0.2139 / \mathrm{ssm} .3602755$

22. Powell DJ, Xirasagar S. Excess Deaths Among the Uninsured Before the Affordable Care Act (ACA), and Potential Post-ACA Reductions: J Public Health Manag Pract. 2017;23(3):e18-e28. doi:https://doi.org/10.1097/PHH. 0000000000000428

\section{Publisher's Note}

Springer Nature remains neutral with regard to jurisdictional claims in published maps and institutional affiliations.

Ready to submit your research? Choose BMC and benefit from:

- fast, convenient online submission

- thorough peer review by experienced researchers in your field

- rapid publication on acceptance

- support for research data, including large and complex data types

- gold Open Access which fosters wider collaboration and increased citations

- maximum visibility for your research: over $100 \mathrm{M}$ website views per year

At BMC, research is always in progress.

Learn more biomedcentral.com/submissions 